\title{
Scale model for the confluent area of debris flow and main river: a case study of the Wenjia Gully
}

\author{
J. Zhang ${ }^{1,2}$, Z. X. Guo ${ }^{2}$, S. Y. Cao ${ }^{2}$, and V. P. Singh ${ }^{3}$ \\ ${ }^{1}$ School of Energy and Environment, Xihua University, Chengdu, 610039, China \\ ${ }^{2}$ State Key Laboratory of Hydraulics and Mountain River Engineering, Sichuan University, Chengdu, 610065, China \\ ${ }^{3}$ Biological \& Agricultural Engineering Department and Civil and Environmental Engineering Department, \\ Texas A\&M University, Texas 77843-2117, USA
}

Correspondence to: Z.X. Guo (scugzx@163.com)

Received: 1 September 2012 - Published in Nat. Hazards Earth Syst. Sci. Discuss.: -

Revised: 14 August 2013 - Accepted: 24 August 2013 - Published: 2 December 2013

\begin{abstract}
When debris flow discharges into the main river, the deposition of debris raises the river bed, occupies the path of water conveyance and damages or even destroys buildings, resulting in considerable economic loss and possibly fatalities. Mathematical models are normally employed to compute debris flow. However, most of these models employ empirical formulae and coefficients and their results are seldom reliable. On the other hand, scale model tests associated with debris flow have seldom been conducted due to the lack of corresponding similarity laws and the difficulty of achieving the grain diameter scale. Focusing on pseudo-one-phase flow, this paper discusses the laws of similarity for the confluence of debris flow and main river and conducts a case study of the debris flow that occurred on 13 August 2010, in the Wenjia Gully, China. After satisfying the roughness scale, the kinematic viscosity coefficient scale, and the momentum ratio scale, it was found that the deposition terrain in the model test is consistent with the one in the prototype.
\end{abstract}

\section{Introduction}

Debris flows represent one kind of geo-hazards and are intermediate between landslides, rockfalls and fluvial sediment transport. They occur widely in hilly areas all over the world (Iverson, 1997). For example, in China nearly $70 \%$ of the territory covered by mountains is susceptible to debris flows, therefore this makes China one of the countries suffering most from this hazard.
Many decades of empirical observations show that debris flows occur abruptly and possess a capacity for huge destruction (Takahashi, 1991; Scott et al., 2001). Not only are the houses, buildings, farmlands, and infrastructure found in their way destroyed or buried, but also the inhabitants are place at risk when not evacuated in time (Liu and Lei, 2003). Sometimes the debris flow discharging into the main river may block the river and form a dam, adversely influencing the regular operation of the hydropower stations upstream and threatening the towns or cities downstream in the case of a dam break. The fluvial processes can be altered because of the deposition remaining on the river bed (Lee, 1990). The various social and economic problems caused by the confluence of debris flow and main river have led to considerable interest in the understanding of these confluent areas, flume experiments, field surveys, statistical research and risk management (Rickenmann et al., 2003; Benda, 1990; Benda et al., 2004; Miller and Burnett, 2008) have therefore been conducted. Mathematical modeling has been a convenient and popular method for describing debris flows, but its applicability is limited due to the introduction of empirical formulas and parameters for the lack of generating mechanisms of debris flows (Rickenmann, 1999; Fuchs et al., 2008). In addition, the majority of mathematical models consider a single fluid (Brufau et al., 2000; Rickenmann et al., 2006), and hence they cannot address the problem due to the confluence of debris flow and main river.

Physical-scale modeling is another alternative to reproduce, evaluate and predict debris flow. Unfortunately, only a few scale model tests have been conducted due to the lack 
of similarity laws. During the 1980s through the 1990s, some researchers discussed the similarly laws of debris flow (Armanini, 1991; Davies, 1993), but most of the tests conducted for debris flows were associated with considerable transport of coarse sediment (Costa, 1984) and typically produced relatively thin, wide sheets of material (Hungr et al., 2001). The similarity laws of these were based on those of ordinary sediment-laden water (for instance, Xu et al., 2000), which contains sediment material no more than $4 \%$ by volume. For ordinary sediment-laden water the number that represents the ratio of inertia force and gravity force was required to be exactly satisfied. Iverson and Denlinger (2001) assessed the dimensionless scaling parameters of the grain-water twophase flows and concluded that a miniature laboratory poorly simulated the dynamics of full-scale flows in which fluid effects were significant. For viscous debris flows, which contain considerable cohesive materials and are characterized by high density $\left(\geq 1.8 \times 10^{3} \mathrm{~kg} \mathrm{~m}^{-3}\right)$, similarity laws were suggested by considering hyper-concentrated flow as a reference based on the hypothesis that both of them belonged to the Bingham plastic fluid (Zhang et al., 1995; Whipple, 1997). However, different from hyper-concentrated flows, viscous debris flows possess higher density and wider grain-size distribution (probably contain gravel and rock). These two external factors make them essentially different in proportions of particle stress, which is composed of friction stress, dispersion stress, and collision stress. In viscous debris flows, the collision stress and friction stress account for a greater portion of the particle stress than those in hyper-concentrated flows. As a result, the value of reference is very little, especially when the density of viscous debris flow is so high that the friction stress becomes the dominating parameter in the particle stress due to relatively low water content. In that case, the fluid is no longer driven by water.

In order to justify the physical-scale modeling for debris flow and find a feasible method to perform a scale model test of confluent area, this paper discusses similarity laws for scale modeling of viscous debris flow discharging into the main river and presents a case study for the debris flow that occurred on 13 August, 2010, in the Wenjia Gully, China.

\section{Confluence of debris flow and main river}

\subsection{Pseudo-one-phase flow assumption}

The shear stress of water-sediment flow can be expressed as (Zhu, 1995)

$\tau=\left(\tau_{\text {friction }}+\tau_{\text {dispersion }}+\tau_{\text {collision }}\right)+(\eta+\varepsilon) \frac{\mathrm{d} u}{\mathrm{~d} y}$,

where $\tau$ is the shear stress of water-sediment flow in $\mathrm{Pa} ; \eta$ is the stiffness coefficient in Pas and $\eta \times(\mathrm{d} u / \mathrm{d} y)$ is the shear stress stemming from viscosity; $\varepsilon$ is the eddy-viscosity coefficient in $\operatorname{Pas}$ and $\varepsilon \times(\mathrm{d} u / \mathrm{d} y)$ is the shear stress stemming from turbulence; $\tau_{\text {friction }}, \tau_{\text {dispersion, }}$, and $\tau_{\text {collision }}$ represent three types of stress between particles, i.e., friction stress, dispersion stress, and collision stress, respectively. Apparently, $\tau_{\text {friction }}$ and $\tau_{\text {collision }}$ are generated due to the friction and impact phenomenon when the particles contact with each other, while $\tau_{\text {dispersion }}$ is induced by position exchange among the particles. The sum of these three items is the apparent yield stress, $\tau_{B}$.

For 2-D steady flow, $\tau_{B}$ is composed of $\left(\tau_{B}\right)_{x y}$ and $\left(\tau_{B}\right)_{y y}$, where $x$ is the streamwise coordinate and $y$ is the coordinate that is perpendicular to $x$ and starting from the river bed (Ni and Wang, 1998). $\tau_{\text {friction }}$ is determined by the normal stress $\sigma$ and the internal friction angle $\varphi$ (Johnson and Jackson, 1987; Eqs. 2a, b).

$$
\begin{aligned}
& \left(\tau_{\text {friction }}\right)_{x y}=\sigma \sin \varphi \\
& \left(\tau_{\text {friction }}\right)_{y y}=\sigma
\end{aligned}
$$

From the experimental research, Wang (1989) has proved that the normal stress $\sigma$ is a function of sediment concentration by volume, $C$ (Eq. 3).

$$
\sigma=\left(\frac{C_{\mathrm{vm}}^{\prime}}{C_{\mathrm{vm}}^{\prime}-C}-1\right) \rho_{\mathrm{p}} D^{3 / 2} \frac{\mathrm{d} u}{\mathrm{~d} y}\left(0.7 g^{1 / 2}+0.5 D^{1 / 2} \frac{\mathrm{d} u}{\mathrm{~d} y}\right),
$$

where $C_{\mathrm{vm}}^{\prime}$ is the limit sediment concentration by volume; $\rho_{\mathrm{p}}$ is the particle density; $D$ is the particle diameter; $\mathrm{d} u / \mathrm{d} y$ is the velocity gradient of the fluid; and $g$ is the acceleration due to gravity. As Eq. (3) shows, $\sigma$ will monotonically increase as the value of $C$ increases. $\mathrm{Ni}$ et al. (1991) deduced $\tau_{\text {dispersion }}$ and $\tau_{\text {collision }}$ in such a way that resembled the kinetic theory of dense gas. From the research of Ni et al. (1991), it can be concluded that $\tau_{\text {friction }}$ and $\tau_{\text {collision }}$ have a positive correlation with $C$, whereas $\tau_{\text {dispersion }}$ has a negative correlation. According to Ni et al.'s theoretic analysis (1991), the composition of $\tau_{B}$ varies as $C$ increases and can be stated as follows: (1) when $C<0.04, \tau_{\text {dispersion }} / \tau_{\text {collision }}>10$. The water-sediment flow is still in the scope of the Newtonian fluid. (2) When $C>0.17, \tau_{\text {dispersion }} / \tau_{\text {collision }}<1$. $\tau_{\text {collision }}$ rises to the dominant element of $\tau_{B}$ and the water-sediment flow belongs to the Bingham fluid. (3) When $C>0.35$, $\tau_{\text {dispersion }} / \tau_{\text {collision }}<0.1$. The concentrated flow transforms into a debris flow where $\tau_{\text {friction }}$ and $\tau_{\text {collision }}$ are the controlling factors. Thus, the fluvial sediment transport theory is invalid for debris flow. Based on the analysis of Yellow River data, Sha (1965) assumed the critical value for debris flood as 0.3 and the weights of both water and particles were the same in that case.

Furthermore, the debris flow will turn into a viscous debris flow when $C$ exceeds the upper limit of the transition region $C_{\text {upl }}\left(C_{\text {upl }}=0.43\right.$ was suggested by Zhu, 1995). Due to the large amount of particles, the space among the solid particles is so small that $\tau_{\text {collision }}$ is limited, whereas $\tau_{\text {friction }}$ is much more considerable. Once $C>0.658$, the viscous debris flow moves downstream mainly under the potential energy of the solid rather than the drag force from the water. If the limiting 
diameter $D_{\max }$ of the neutrally suspended load is larger than the maximum diameter of the particles in viscous debris flow, this mixture flow acts like one-phase flow and can therefore be considered as a pseudo-one-phase flow. In that case, the water content is very low and the density of viscous debris flow is extremely high. Then, water just plays the role of a lubricant in the movement, not of a carrier.

For a pseudo-one-phase flow, neither the similarity laws of ordinary sediment-laden water nor of hyper-concentrated flow are appropriate. In particular, the confluence of debris flow and main river needs the consideration of the ratio of their momentum values.

\subsection{Similarity laws}

The focus here is on viscous debris flow with high density, assumed as pseudo-one-phase flow. The basic equations of single incompressible viscous flow are as follows:

continuity equation $\frac{\partial u}{\partial x}+\frac{\partial v}{\partial y}+\frac{\partial w}{\partial z}=0$,

motion equation (in the $x$ direction)

$\frac{\partial u}{\partial t}+u \frac{\partial u}{\partial x}+v \frac{\partial u}{\partial y}+w \frac{\partial u}{\partial z}=g_{x}-\frac{1}{\rho} \frac{\partial p}{\partial x}+v \nabla^{2} u$,

where $u, v, w$ are the velocity components in the $x, y, z$ directions, respectively; $p$ is the pressure and can be neglected in open channel; $g_{x}$ is the acceleration component of gravity in the $x$ direction; $v$ is the kinematic viscosity coefficient; and the Laplace operator $\nabla^{2}=\frac{\partial^{2}}{\partial x^{2}}+\frac{\partial^{2}}{\partial y^{2}}+\frac{\partial^{2}}{\partial z^{2}}$.

The geometrical scale of a normal model should satisfy $\frac{x_{\mathrm{p}}}{x_{\mathrm{m}}}=\frac{y_{\mathrm{p}}}{y_{\mathrm{m}}}=\frac{z_{\mathrm{p}}}{z_{\mathrm{m}}}=\lambda_{l}$, and $\lambda_{1}$ is the ratio between the value in the model and the value in the prototype. Using the value of the model and the scales, the basic equations can be transformed as follows:

$$
\begin{aligned}
\frac{\lambda_{u}}{\lambda_{l}}\left(\frac{\partial u_{\mathrm{m}}}{\partial x_{\mathrm{m}}}+\frac{\partial v_{\mathrm{m}}}{\partial y_{\mathrm{m}}}+\frac{\partial w_{\mathrm{m}}}{\partial z_{\mathrm{m}}}\right)=0, \\
\begin{aligned}
\frac{\lambda_{u}}{\lambda_{t}} \frac{\partial u_{\mathrm{m}}}{\partial t_{\mathrm{m}}} & +\frac{\lambda_{u}^{2}}{\lambda_{l}}\left(u_{\mathrm{m}} \frac{\partial u_{\mathrm{m}}}{\partial x_{\mathrm{m}}}+v_{\mathrm{m}} \frac{\partial u_{\mathrm{m}}}{\partial y_{\mathrm{m}}}+w_{\mathrm{m}} \frac{\partial u_{\mathrm{m}}}{\partial z_{\mathrm{m}}}\right) \\
& =\lambda_{g} g_{x_{\mathrm{m}}}-\frac{\lambda_{\mathrm{p}}}{\lambda_{\rho} \lambda_{l}} \frac{1}{\rho_{\mathrm{m}}} \frac{\partial p_{\mathrm{m}}}{\partial x_{\mathrm{m}}}+\frac{\lambda_{v} \lambda_{u}}{\lambda_{l}^{2}} v_{\mathrm{m}} \nabla^{2} u_{\mathrm{m}} .
\end{aligned}
\end{aligned}
$$

Only if the coefficient of every item in Eqs. (6) and (7) is equal to 1 , will the phenomenon in the model be similar to the one in the prototype. Then $\lambda_{u}^{2} / \lambda_{l}$ is utilized to divide every item in Eq. (7), producing Eq. (8).

$\frac{\lambda_{u} \lambda_{t}}{\lambda_{l}}=\frac{\lambda_{u}^{2}}{\lambda_{g} \lambda_{l}}=\frac{\lambda_{\mathrm{p}}}{\lambda_{\rho} \lambda_{u}^{2}}=\frac{\lambda_{u} \lambda_{l}}{\lambda_{v}}=1$,

where these four dimensionless numbers are well known as the Strouhal number, Froude number, Euler number and
Reynolds number, respectively. Ignoring the Euler number, other scales derived from Eq. (8) are listed in Table 1.

In combining open channel flow (water flow/water flow), the characteristic parameters of the junction area are usually driven in hydraulics by the momentum principle (Biron et al., 1996), for example, the relation between the depth of flow at the junction and the ratio of the lateral discharge to the total discharge (Ramamurthy, 1988). This concept can also been extended to the junction of water flow/debris flow. As regards the confluence of debris flow and main river, the interaction similarity in the junction area is very important. The confluence process is associated with boundary conditions, motion characteristics and flow properties of both water and debris flow. The boundary condition similarity can be easily achieved by satisfying the geometric scale and roughness scale. With respect to the motion characteristics and flow properties of both fluids, the momentum ratio (Eq. 9) involves these two aspects and is defined as the ratio between the momentum value per unit time of debris flow $\rho_{s} Q_{s} U_{s}$, and the momentum value per unit time of main river $\rho Q U$. Terms $\rho_{s}, Q_{s}$, and $U_{s}$ are the density, discharge and crosssection average velocity of debris flow, respectively; and $\rho$, $Q$, and $U$ are the density, discharge and cross-section average velocity of main river, respectively.

$M_{*}=\rho_{s} Q_{s} U_{s} / \rho Q U$

Generally, the momentum ratio exhibits the interaction between debris flow and main river. Debris flow obviously deforms river bed elevation and constricts flow path when discharging into the main river. Conversely, the current in the main river hinders the extension of debris flow due to the water pressure and entrains some sediment of the deposit. In order to depict the interaction process completely, $\lambda_{M *}$ should satisfy:

$\lambda_{M_{*}}=1$.

One problem that should be mentioned here is that the unsteady condition of debris flow becomes a complication when dealing with the momentum ratio conservation. Owing to the most destruction, the peak condition of debris flow is usually paid the most attention during the whole process. In view of that, the peak parameters are utilized in this momentum ratio conservation.

\section{Case study}

\subsection{Event description}

A catastrophic debris flow occurred on 13 August 2010, in the Qingping area located in the city of Mianzhu, $83 \mathrm{~km}$ away from Chengdu (Fig. 1), southwestern China. After torrential rains, debris flows were triggered simultaneously in eleven gullies along the Mianyuan River (Fig. 2). The 
Table 1. Scale for the confluence of debris flow and the main river.

\begin{tabular}{|c|c|c|c|c|c|c|}
\hline $\begin{array}{l}\text { Similarity } \\
\text { scale }\end{array}$ & $\begin{array}{c}\text { Velocity } \\
\text { scale } \\
\lambda_{u}\end{array}$ & $\begin{array}{c}\text { Time scale } \\
\lambda_{t}\end{array}$ & $\begin{array}{c}\text { Discharge } \\
\text { scale } \\
\lambda_{Q}\end{array}$ & $\begin{array}{c}\text { Kinematic viscous } \\
\text { coefficient scale } \\
\lambda_{v}\end{array}$ & $\begin{array}{c}\text { Roughness } \\
\text { scale } \\
\lambda_{n}\end{array}$ & $\begin{array}{c}\text { Momentum } \\
\text { ratio scale } \\
\lambda_{M_{*}}\end{array}$ \\
\hline Equations & $\lambda_{l}^{1 / 2}$ & $\lambda_{l}^{1 / 2}$ & $\lambda_{l}^{5 / 2}$ & $\lambda_{l}^{3 / 2}$ & $\lambda_{l}^{1 / 6}$ & 1 \\
\hline
\end{tabular}

largest and most harmful debris flow was from the Wenjia Gully of which the outlet coordinates are $31^{\circ} 33^{\prime} 04.7^{\prime \prime} \mathrm{N}$, $104^{\circ} 06^{\prime} 58.5^{\prime \prime} \mathrm{E}$ and the altitude is $883 \mathrm{~m}$. The debris flow discharging into the Mianyuan River destroyed the Xinfu Bridge and occupied the path of flow (Fig. 2). According to the investigation report of the Wenjia Gully prepared by Sichuan Surveying and Design Institute of Water Resources (referred to as SSDIWR, 2010), the duration of debris flow was $2.5 \mathrm{~h}$; the maximum thickness of deposition was larger than $15 \mathrm{~m}$; and discharge of the Mianyuan River was $300 \mathrm{~m}^{3} \mathrm{~s}^{-1}$. The total volume $\left(450 \times 10^{4} \mathrm{~m}^{3}\right)$ of the debris flow from the Wenjia Gully was generated in Golden Software Surfer with topographic data in the form of CAD files provided by SSDIWR (2010). Yu et al. (2010) analyzed the data provided by the Geologic Engineering Office of Chengdu (referred to as GEOC) and concluded that the density of debris flow was $2.22 \times 10^{3} \mathrm{~kg} \mathrm{~m}^{-3}$ and the yield stress $\tau_{B}$ was $10029 \mathrm{~Pa}$. Through the verification with the well-documented debris flow event that occurred on 18 September 2010, the Schoklitsch (1950) formula was employed by Yu et al. (2010) to evaluate the peak discharge of debris flow on $13 \mathrm{Au}$ gust 2010. All the parameters of the Wenjia Gully debris flow on 13 August 2010 are summarized in Table 2. The grain-size distributions of deposition were collected from the two organizations (SSDIWR and GEOC) and are drawn in Fig. 3.

In Fig. 3, the data from the investigation report of SSDIWR shows that the sediment-sorting characteristic can be observed in the deposition of debris flow from the Wenjia Gully. The median grain size diameter $D_{50}$ in the coarsegrains region near the outlet of the gully was $18 \mathrm{~mm}$, and in the fine-grains region far from the outlet of the gully, it was $10 \mathrm{~mm}$. It seems that the debris flow was not pseudo-onephase flow. However, the investigation started after $23 \mathrm{Au}-$ gust 2010 before which another torrential rain had occurred on 19 August lasting $11 \mathrm{~h}$ and the total amount of rainfall was $172.6 \mathrm{~mm}$ (the total amount of rainfall on 13 August lasting for $9 \mathrm{~h}$ was $227 \mathrm{~mm}$ ). The rainfall data was obtained from the Nanmu Hydrological Station $6 \mathrm{~km}$ away from the Wenjia Gully. Nearly $300 \times 10^{3} \mathrm{~m}^{-1 / 3} \mathrm{~s}$ of debris flow ran out of the gully on 19 August. As a result, the surface layer of the old deposition was perhaps scoured by the later rainfall and the sediment, especially the fine sediment, could have been transported downstream by the overland runoff. According to Yu et al. (2010), one curve was enough to exhibit the grainsize distribution of deposition (the data from GEOC). Additionally, the sediment characteristic of deposition in the

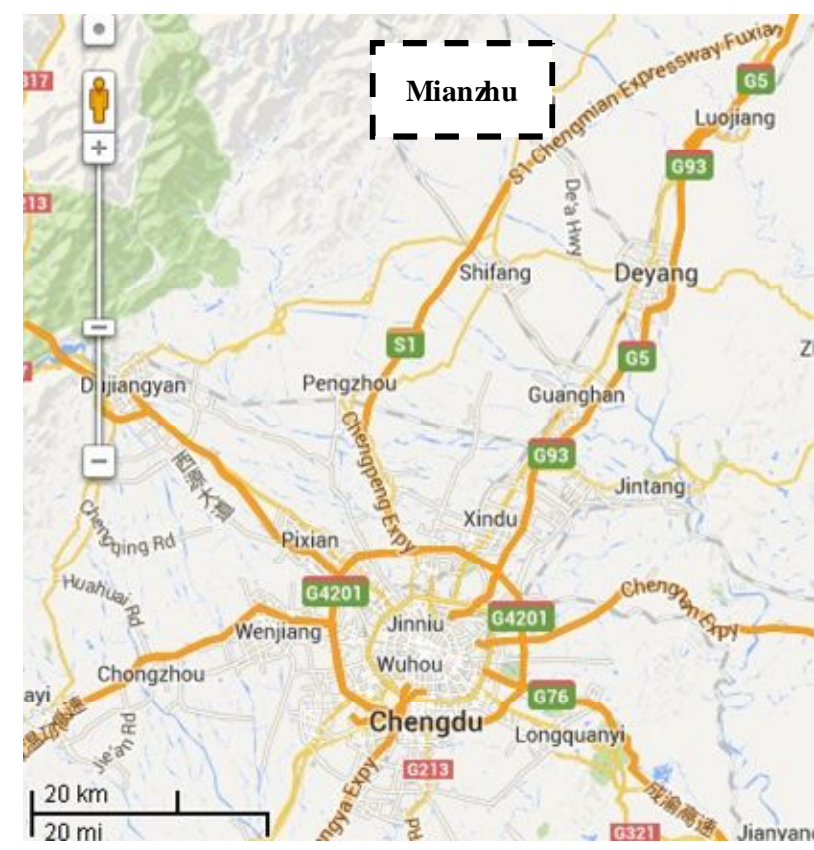

Fig. 1. The geographic location of the study area (from Google).

Wenjia Gully on 13 August was hybrid sediment (gravel, sand and clay were mixed up on the deposition profile), which is consistent with the feature of pseudo-one-phase flow described by Wang et al. (2001).

The limiting diameter $D_{\max }$ of the neutrally suspended load can be calculated as (Qian and Wan, 1985)

$D_{\max }=5.7 \frac{\tau_{B}}{\gamma_{\mathrm{s}}-\gamma_{\mathrm{f}}}$

where $\gamma_{\mathrm{f}}$ provided by the slurry consisting of fine grains and water, is the buoyancy force acting on the unit volume of particles with diameter $D_{\max }$. The low limit density of viscous debris flow, $1.8 \times 10^{3} \mathrm{~kg} \mathrm{~m}^{-3}$, was employed to define $\gamma_{\mathrm{f}} \cdot \gamma_{\mathrm{s}}$ is the sediment density, $2.22 \times 10^{3} \mathrm{~kg} \mathrm{~m}^{-3}$. According to Table $2, \tau_{B}=10.029 \mathrm{kPa}$. Using Eq. (11), $D_{\max }$ is $136.11 \mathrm{~mm}$ beyond the grain-size range of Yu et al.'s (2010) investigation and is equal to $D_{95}$ of the report's grain-size distribution. That means that with Yu et al.'s (2010) data all the particles in the debris flow were neutrally suspended flowing in unison with water. There is no doubt about the assumption of pseudo-one-phase flow; with the data from the report (SSDIWR, 2010), only 1/20 of sediment in weight 
Table 2. Parameters of debris flow.

\begin{tabular}{cccccc}
\hline Duration $[\mathrm{s}]$ & $\begin{array}{c}\text { Volume } \\
{\left[10^{4} \mathrm{~m}^{3}\right]}\end{array}$ & $\begin{array}{c}\text { Peak discharge } \\
{\left[\mathrm{m}^{3} \mathrm{~s}^{-1}\right]}\end{array}$ & $\begin{array}{c}\text { Density } \\
{\left[\times 10^{3} \mathrm{~kg} \mathrm{~m}^{-3}\right]}\end{array}$ & $\begin{array}{c}\text { Sediment concentration } \\
\text { in volume }\end{array}$ & $\begin{array}{c}\text { Yield } \\
\text { stress }[\mathrm{Pa}]\end{array}$ \\
\hline 9000 & 450 & 1530 & 2.22 & 0.72 & 10029 \\
\hline
\end{tabular}

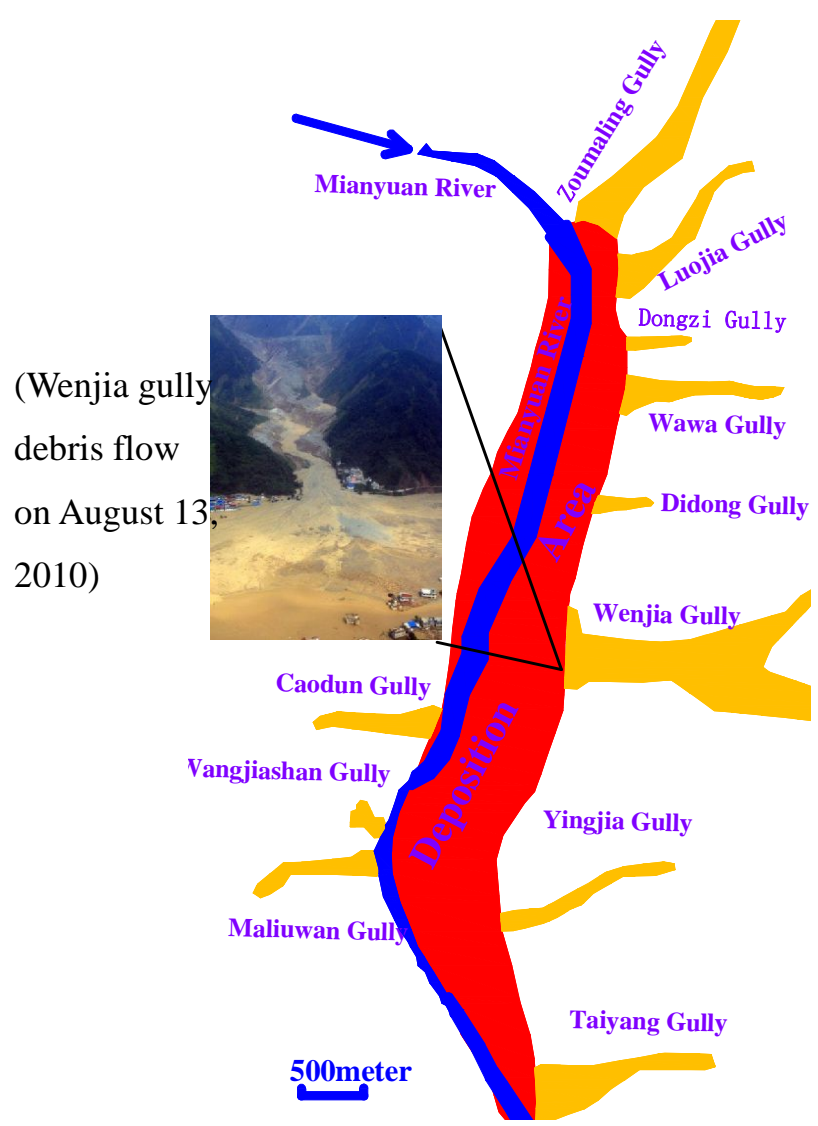

Fig. 2. Distribution of gullies in Qingping (Xu et al., 2012).

was transported in the form of suspend and bed load. The other sediment and water constituted the one-phase flow with 0.036 "sediment" concentration by volume, which is so small that this "sediment" could be ignored. As a result, it is reasonable to assume that the debris flow that occurred on 13 August 2010 in the Wenjia Gully was a pseudo-one-phase flow.

\subsection{Scope of investigation}

Considering the available space in the experimental site, the geometric scale $\lambda_{l}$ was $1: 400$ and only the confluence area of debris flow and main river was studied. The channel of the model was from the Yinxing Bridge upstream to Happiness House downstream (Fig. 4). The overall length was $4 \mathrm{~km}$, and the average width approximated $800 \mathrm{~m}$. The gully of the model was from the check dam to the outlet, $620 \mathrm{~m}$

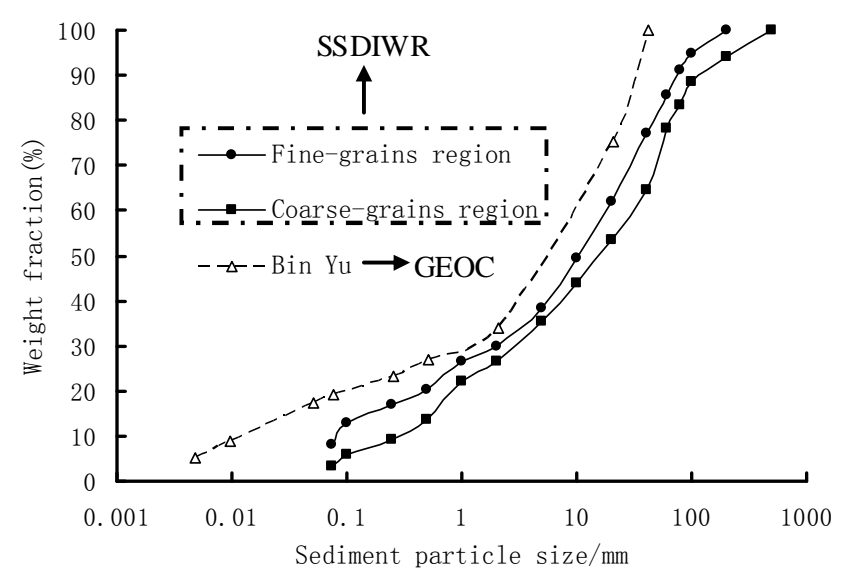

Fig. 3. Grain-size distribution of deposition.

long and $220 \mathrm{~m}$ wide. The specific similarity scales are listed in Table 3.

\subsection{Apparatus}

The model was constructed in the sediment model test hall of Sichuan University. The sketch map of the model is given in Fig. 5. Before the test, a sample of debris flow was conserved in a box of which the volume was $188.5 \mathrm{~L}$. The gate of the box was $1 \mathrm{~cm}$ high and $13 \mathrm{~cm}$ wide. The diversion trench was $1 \mathrm{~m}$ long, $13 \mathrm{~cm}$ wide with a $13.43^{\circ}$ slope, which is measured with a water level instrument and is quite close to the average slope of the flow path, $13.13^{\circ}$, in the prototype (Liu, 2012). The terrain before and after the test was measured with an electronic total station. Then, the deposition thickness contour map was generated by the comparison of two measurements. The overall process of the experiments was videotaped with a Sony camera.

\subsection{Model scale}

\subsubsection{Roughness of the model}

The roughness of the study area included the channel roughness and the gully roughness. For the channel roughness, empirical experience and the water surface iteration method were often utilized due to the lack of field data. The Mianyuan River is a mountain river with an average gradient of $0.86 \%$, and the channel is primarily composed of gravel and pebbles. According to the lookup table of channel roughness (Wu and Huang, 1986), $0.045 \mathrm{~m}^{-1 / 3} \mathrm{~s}$ is a recommended 
Table 3. Similarity scales of the model.

\begin{tabular}{lcccccc}
\hline & Velocity & & Discharge & Kinematic viscous & Roughness & Momentum \\
Similarity & scale & Time scale & scale & coefficient scale & scale & $\lambda_{v}$ \\
scale & $\lambda_{u}$ & $\lambda_{t}$ & $\lambda_{Q}$ & $\lambda_{v}$ & $\lambda_{n}$ & $\lambda_{M_{*}}$ \\
\hline Scale value & 20 & 20 & 3200000 & 8000 & 2.714 & 1 \\
\hline
\end{tabular}

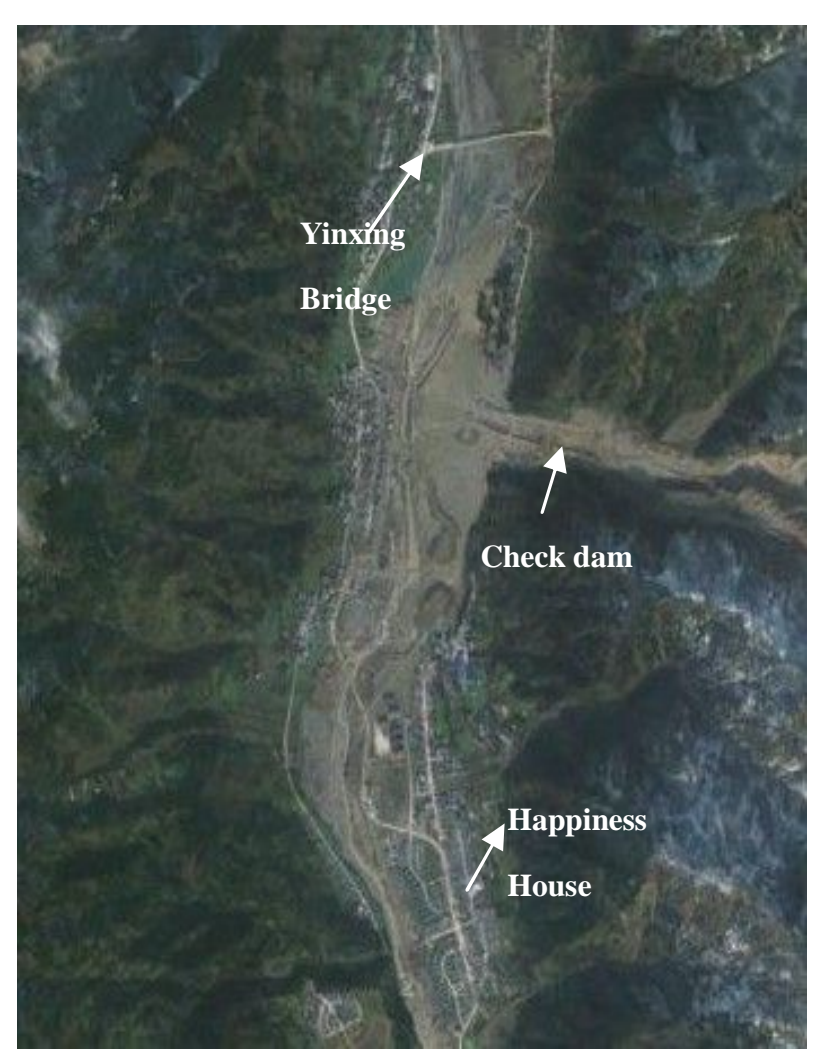

Fig. 4. Satellite image of the study area in detail (from Google).

value of the main river. Thus, the channel roughness in the model should be $0.0166 \mathrm{~m}^{-1 / 3} \mathrm{~s}$. With the historic data of water level in the $10 \%$ frequency flood at the control section, the corresponding water level in the model is known. By comparing the calculated value of the water level and the measured data, one can judge whether the roughness in the model is similar to that in the prototype or not. This process is called "water surface check". The actual roughness of channel in the model, $0.0173 \mathrm{~m}^{-1 / 3} \mathrm{~s}$, was determined through the inverse calculation with the Manning formula. The deviation $+4.2 \%$ was acceptable.

For the gully roughness, the value was assumed to be the same as the channel roughness. There are three reasons to support this method. Firstly, the length of the gully covered by the study scope was relatively short, especially for the part in which the debris flow could pass. Secondly, the gully is almost dry unless a rainstorm occurs. No historical data

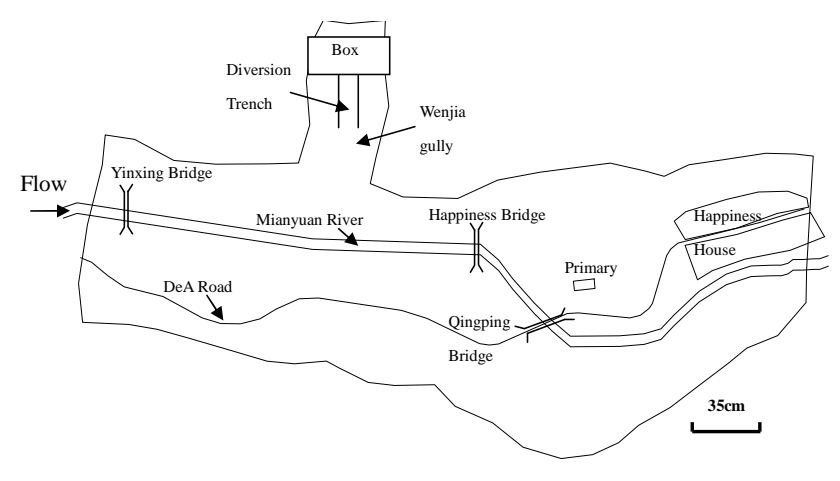

Fig. 5. Sketch of model test.

therefore can be inquired for "water surface check". Thirdly, the outlet of the gully was smoothed by the antecedent deposit since four debris flows had occurred before 13 August. As a result, the gully's roughness could be considered the same as the channel roughness even though the sediment on the gully before debris flows was bigger than that on the main river.

\subsubsection{Sample of debris flow}

Because of the assumptions in Sect. 3.1, the debris flow of the Wenjia Gully on 13 August 2010 was a pseudo-one-phase flow. The wide range of grain-size distributions and diameter scales were beyond the scope of consideration, greatly reducing the sample preparation work. The major work for sample preparation was to achieve the kinematic viscosity coefficient scale, while the clay concentration and water content were the important factors in controlling $v$. After several trials, $25.8 \%$ water content and $13 \%$ clay concentration in quantity were determined for the sample. The density of the sample was $1.85 \times 10^{3} \mathrm{~kg} \mathrm{~m}^{-3}$, and the volume was $70.315 \mathrm{~L}$.

Since $v=\mu / \rho$, the apparent viscosity coefficient $\mu$ was used to check the kinematic viscosity coefficient scale in the model. Although debris flow is widely accepted as the Bingham fluid, its rheological curve is not a typical one of the Bingham fluid (Fig. 6). The plug flow shows a great apparent viscosity $\mu_{\mathrm{a}}$ at the initial stage. With the increase in shear rate, the flow structure is gradually destroyed, leading to the complete laminar flow in which the shear stress is only influenced by shear rate. During the laminar flow stage, the rheological curve is a straight line with interception on the $y$ axis and $\mu_{\mathrm{a}}$ is close to the plastic viscosity coefficient. Thus, it is 
appropriate to adopt $\mu_{\mathrm{a}}$ of laminar flow for the calculation of $\lambda_{v}$.

The relation of apparent viscosity $\mu_{\mathrm{a}}$ and sediment concentration in volume $C_{\mathrm{V}}$ was established by Wang (1982) (Eq. 12). The scale equation corresponding to $\mu_{\mathrm{a}}$ can be easily obtained from its definition (Eq. 13).

$\mu_{\mathrm{a}}=0.0076 e^{18.692 C_{\mathrm{V}}}$

$\lambda_{\mu_{\mathrm{a}}}=\lambda_{v} \cdot \lambda_{\rho}$

Upon substitution of $C_{\mathrm{V}}=0.72$ into Eq. (13), $\mu_{\mathrm{a}}$ in the prototype is $5316.832 \mathrm{~N} \mathrm{~s} \mathrm{~m}^{-2}$ and because $\lambda_{\rho}=\gamma_{\mathrm{p}} / \gamma_{\mathrm{m}}=1.2$, $\lambda_{v}=\left(\lambda_{l}\right)^{3 / 2}=400^{3 / 2}=8000, \lambda_{\mu_{\mathrm{a}}}=9600$. Consequently, $\mu_{\mathrm{a}}$ in the model should be $0.554 \mathrm{~N} \mathrm{~s} \mathrm{~m}^{-2}$.

A physical MCR modular rheometer made by the Anton Paar Company, Austria, was applied to test the rheological characteristics of the debris flow sample from which the coarse grains $(d>0.5 \mathrm{~mm})$ had been removed. With the rheological curve of the sample in Fig. 6, the average apparent viscosity coefficient $\mu_{\mathrm{a}}=0.537408 \mathrm{~N} \mathrm{~s} \mathrm{~m}^{-2}$ in laminar flow was obtained. In fact, the existence of removed coarse grains would enhance the flow viscosity by reducing the free interstice ratio and increasing the impact chance among the particles. Therefore, a correction was required for $\mu_{\mathrm{a}}$ and Fei and Zhu's (1986) equation was chosen here (Eqs. 14a and 14b):

$\mu_{\mathrm{a}}^{\prime}=\left(1-\frac{C_{\mathrm{VS}}}{C_{\mathrm{Vm}}^{\prime}}\right)^{-2.5} \mu_{\mathrm{a}}$,

$C_{\mathrm{VS}}=\frac{C_{\mathrm{VT}}}{1+V_{\mathrm{f}} / V_{\mathrm{c}}}$,

where $\mu_{\mathrm{a}}^{\prime}$ is the correct viscosity coefficient; $C_{\mathrm{VS}}$ is the coarse grain concentration in volume; $C_{\mathrm{Vm}}^{\prime}$ is the limit sediment concentration in volume and generally is $0.8 ; C_{\mathrm{VT}}$ is the sediment concentration in volume; and $V_{\mathrm{f}}$ and $V_{\mathrm{c}}$ are the volumes of fine grains $(d<0.5 \mathrm{~mm})$ and coarse grains $(d>0.5 \mathrm{~mm})$, respectively. After the calculation of $C_{\mathrm{VS}}$ by Eq. (14b), $C_{\text {VS }}$ was substituted into Eq. (14a) and $\mu_{\mathrm{a}}^{\prime}=$ $0.645 \mathrm{~N} \mathrm{~s} \mathrm{~m}^{-2}$ was determined, where the deviation was $+16.4 \%$.

\subsubsection{Momentum ratio}

As the gate of the box opened, the debris flow ran out of the gully, then discharged into the main river, and lastly deposited on the river bed in the form of a fan under both the inertial force and the water force. The discharge of debris flow was controlled by the gate height and the slope of diversion trench, if the box size, the density, grain-size distribution and volume of the debris flow had been determined. According to Tables 2 and 3, the peak discharge of debris flow in the model should be $0.478 \mathrm{~L} \mathrm{~s}^{-1}$ and peak velocity should be $11.769 \mathrm{~cm} \mathrm{~s}^{-1}$. Unfortunately, the preparation tests proved that it was impossible to make the debris flow move in such

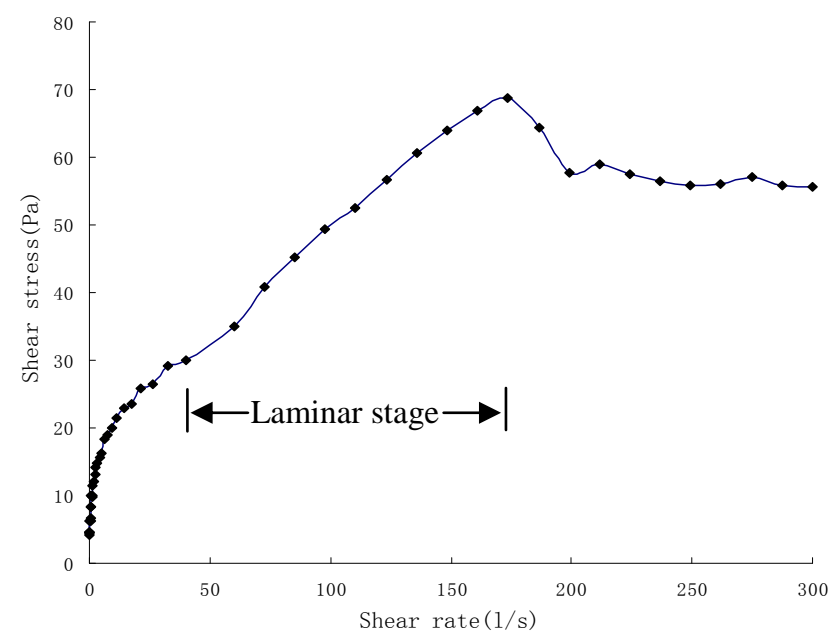

Fig. 6. Rheological curve of debris flow in model.

low velocity with good fluidity. Through the post-processing of the video, the peak velocity $U_{\mathrm{p}}$ was $66.48 \mathrm{~cm} \mathrm{~s}^{-1}$ and the peak discharge $Q_{\mathrm{p}}$ was $0.871 \mathrm{~L} \mathrm{~s}^{-1}$. Thus, the deviation of $U_{p}$ and $Q_{p}$ were +464.86 and $+82.1 \%$, respectively. Obviously, the model could not satisfy the requirements of velocity scale and discharge scale. As a result, the time scale could also not be achieved because of the scale relation with velocity.

The reason why the deviations were huge can be explained in three aspects. Firstly, it was really difficult to implement such a slow debris flow in a small-scale model. Secondly, the peak discharge of debris flow in the prototype was evaluated using the Schoklitsch formula (1950) developed for flooding and the measured data was collected several days after the event. Thirdly, in natural conditions the longitudinal profile of a debris flow shows changes of density over length, forming a coarser debris front and a liquid tail of the flow. This typical feature could be observed on a long enough flow path; while the length of gully covered by the study scope was relatively short, especially the part in which the debris flow should pass.

Alternatively, the momentum per unit time includes these two factors, velocity and discharge. For the scale model of confluence of debris flow and main river, the similarity of $M_{*}$ at peak discharge is the key point.

In the prototype, the discharge of the Mianyuan River, $300 \mathrm{~m}^{3} \mathrm{~s}^{-1}$, was substituted into Eq. (9), yielding $\left(M_{*}\right)_{\mathrm{p}}=$ 8.177. In the model, the river discharge was adjusted accordingly, as the magnified velocity of debris flow. The crosssection average velocity associated with the discharge can be simulated with HEC-RAS (Hydrologic Engineering CenterRiver Analysis System). The steady flow velocity in the river had been raised in the model from 16.15 to $21.05 \mathrm{~cm} \mathrm{~s}^{-1}$ to compensate the out-of-scale debris flow velocity. This alteration corresponds to the prototype velocities of 13.3 and $4.21 \mathrm{~m} \mathrm{~s}^{-1}$ for debris flow and river flow, respectively. The 


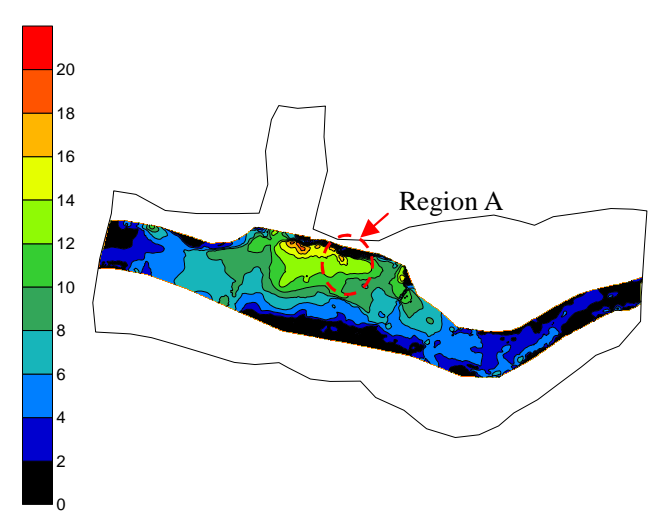

(a)

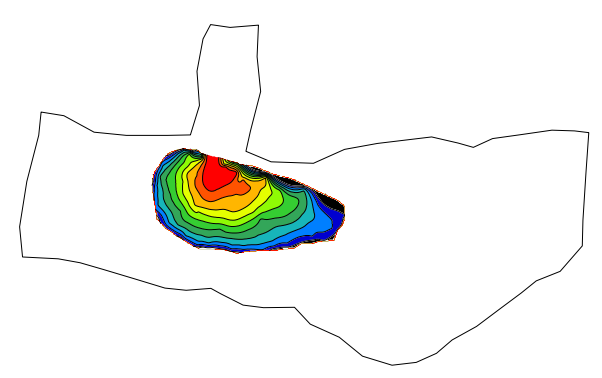

(b)

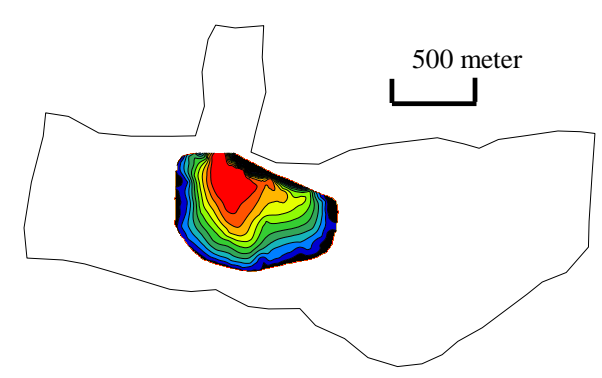

(c)

Fig. 7. Contours of deposit thickness. (a) The contour of the prototype; (b) the contour of the model in which $\lambda_{M *}=1$; and (c) the contour of the model without using the $M$ conservation and in which $Q_{\mathrm{r}}=0$.

discharge of the Mianyuan River, $0.65 \mathrm{~L} \mathrm{~s}^{-1}$, was substituted into Eq. (9), yielding $\left(M_{*}\right)_{\mathrm{m}}=7.89$. The deviation of momentum ratio was $-3.5 \%$.

\subsection{Results}

Due to the lack of field data of debris flow in the Wenjia Gully on 13 August the deposition terrain was the only criterion to judge the result of the scale model test. Figure 7 shows the contours of deposition thickness in the prototype and the model. Figure $7 \mathrm{a}$ was generated from the terrain maps before and after the event provided by SSDIWR (2010). Figure 7b is the thickness contour map of the model respecting the momentum ratio similarity. In order to exhibit the importance of the $M_{*}$ similarity, the contour map of the model without using the $M$ conservation is shown in Fig. 7c. The river discharge $Q_{\mathrm{r}}$ in Fig. 7c is 0. Comparison of the three contour maps in Fig. 7 illustrates that with the $M_{*}$ similarity, the deposition terrain in the model resembles the one in the prototype in general. This can be explained further as follows.

1. Maximum thickness: the maximum thickness of deposition in the prototype was larger than $18 \mathrm{~m}$, nearly $20 \mathrm{~m}$, whereas it has been said that the local deposition region was $26 \mathrm{~m}$ higher than the original river bed (Yu et al., 2010). The accuracy of the contour map could be affected by the method of selecting measured points, grid generation and interpolation. All these factors possibly led the map to lose the maximum thickness. In view of this the maximum thickness of the model, which was $25 \mathrm{~m}$, is consistent with that of the prototype.

2. Deposition range: for the transverse direction along the thalweg of the Wenjia Gully and crossing of the main river, the thickness distributions are shown in Fig. 8. The deposition width was $470.83 \mathrm{~m}$ in the prototype and was $456.67 \mathrm{~m}$ in the model. The deviation of deposition width was only $-3.76 \%$. The thickness for the prototype at the beginning (the outlet of Wenjia Gully) was actually negative because of the regressive erosion in the whole gully, while for the model it was positive due to the fixed model bed. With respect to the model in which $Q_{\mathrm{r}}=0$, the deposition width was $552.25 \mathrm{~m}$ much larger than the prototype one and the deviation was $17.3 \%$.

For the longitudinal direction streamwise, the whole study site was covered by the debris flow in the 


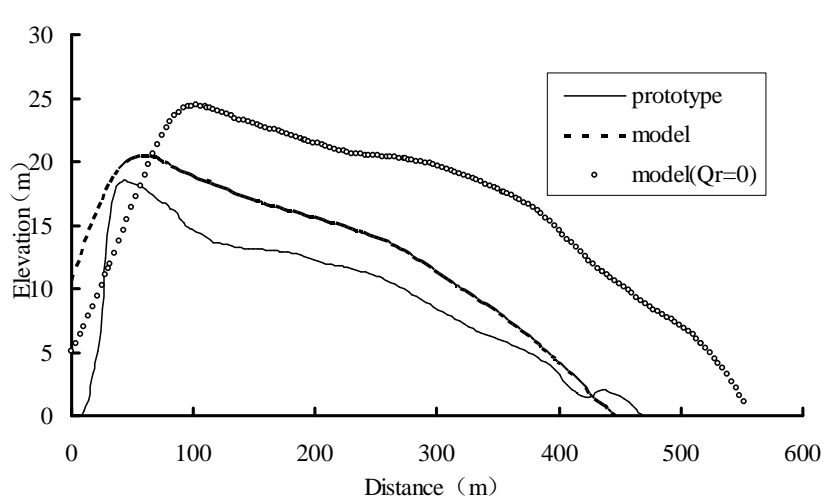

Fig. 8. Transverse deposit profile.

prototype, because the debris flows were triggered in 11 gullies along the river on that day (Fig. 2). Except for the deposition from the Zoumaling Gully and Wenjia Gully, other accumulations were too small to keep the shape due to the erosion from both the main river and rainfall. As the accumulations were vanishing, the eroded sediment was being transported and deposited along the channel. Therefore, Fig. 7a includes the deposition from other gullies, which was hard to distinguish from the deposition of the Wenjia Gully. For example, the contour lines of region A in Fig. 7a are not successive to those upstream because part of the accumulation probably comes from the Caodun Gully adjacent to the Wenjia Gully. Among these ten gullies in Qingping (Fig. 2) only the Taiyang Gully cannot affect the topography of the deposition shown in Fig. 7a since it was located downstream of the Wenjia Gully and not in the scope of research. The total volume of debris flow coming out from the other nine gullies was approximately $150 \times 10^{4} \mathrm{~m}^{3}$ (Xu et al., 2012), while the debris flow from the Wenjia Gully was $450 \times 10^{4} \mathrm{~m}^{3}$ in volume and nearly $20 \mathrm{~m}$ in maximum thickness as stated above. It was therefore assumed that the section of deposition thicker than $7 \mathrm{~m}$ was not mixed with the sediment from other gullies. Focusing on this section, the deposition distributions in the longitudinal profile are shown in Fig. 9. The deposition length was $1099.68 \mathrm{~m}$ in the prototype and $952.20 \mathrm{~m}$ in the model. The deviation of the length was $-13.4 \%$. While the deposition length for the model in which $Q_{\mathrm{r}}=0$ was $796.52 \mathrm{~m}$ and the deviation was $-27.6 \%$.

3. Deposition pattern: the deposition fan in both Fig. 7a and $b$ possessed asymmetry. Compared with the fan in Fig. 7b, the fan in Fig. 7a had a much longer section below the gully outlet and the section thicker than $20 \mathrm{~m}$ was completely located downstream from the outlet. In the transverse profile (Fig. 8), the peak position was close $(56.64 \mathrm{~m}$ in the prototype and $46 \mathrm{~m}$ in the model) but the model thickness was larger in general.

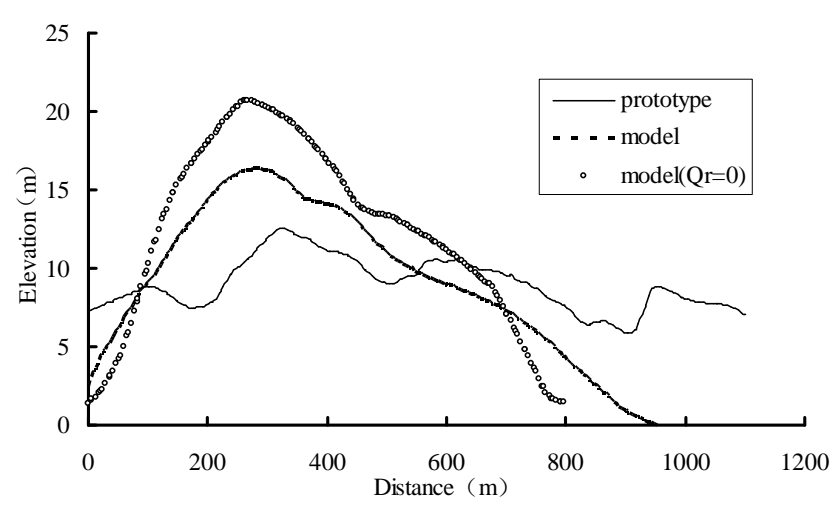

Fig. 9. Longitudinal deposit profile.

In the longitudinal profile (Fig. 9), the model profile was higher than the prototype one in the intermediate part but lower in the upstream and downstream part. Obviously, the deposition fan in the prototype was deformed under gravity force over several days and became gentler.

With respect to the model of $Q_{\mathrm{r}}=0$, the peak position in the transverse profile (Fig. 8) was $102.66 \mathrm{~m}$ from the outlet of the gully. Compared with the fans in the model $\left(M_{*}=1\right)$ and the prototype, the debris flow went further to the opposite bank of the main river rather than downstream. The momentum of the main river was a considerable factor for the development of the deposition fan of the debris flow running out from the tributary channel. Lacking of the constraint from the main river makes the fan overdevelop in the transverse direction and underdevelop in the longitudinal profile. The model in which $Q_{\mathrm{r}}=0$ therefore did not agree as well with the prototype as the model with the $M$ conservation did. It is proved that the $M_{*}$ similarity is quite important for the scale model of junction.

\subsection{Discussion}

From the comparison of the deposit fans in Fig. 7a and b, some deviations can still be observed. The differences may be caused by several reasons as follows.

a. A well-done survey just after the event is quite important for research, but is not easily accomplished after a catastrophic disaster has occurred. As mentioned previously, the survey of the debris flow started several days after the event. The intensive rainfall on $19 \mathrm{Au}$ gust 2010, washed the surface, diluted the density and raised the water content of accumulation. Due to increased fluidity, the debris flow fan was consequently attenuated under the gravity force, especially downstream.

b. The scale of the model was too small to include microtopography and display the complicated boundary 
conditions. For example, a huge rock or antecedent deposition at the outlet of gully could deflect the flow direction.

c. In natural conditions, the density of debris flow is not a constant both in space and time scales. Firstly, the longitudinal profile of a debris flow shows changes of density over length, forming a coarser debris front and a liquid tail of the flow. Secondly, as the flood scours the gully, the debris flood turns into a viscous debris flow due to the increase in sediment concentration. During the late stage, the quantity of solids involved in the flow reduces significantly since the trigger conditions change. With continual rainfall, the debris flow is diluted and the density decreases. The unsteadiness of flow density also affects the deposition fan.

d. The loss of potential energy plays an important role in the runout distance of the debris flow (Vincenzo et al., 2010). Different from most debris flows, avalanches, and collapse, the source area of the debris flow on 13 August in the Wenjia Gully was not only from the platform on the mountain at $1300 \mathrm{~m}$ altitude, but also the whole runout area due to the intensive erosion in the gully (Liu, 2012). Because of the overlap of the source area and the runout area, it is hard to define a correct value for the loss of potential energy. As a result, the value assigned to this model might not be so appropriate and that causes some deviation from the prototype.

\section{Conclusions}

Although effective, scale models associated with debris flow have seldom been conducted due to the lack of similarity laws and the difficulty of achieving the grain diameter scale. For viscous debris flow with extremely high density, $\tau_{\text {collision }}$ and $\tau_{\text {friction }}$ are the controlling factors of the shear stress of water-sediment flow. The mixture flow moves downstream mainly under the potential energy of the solid rather than the drag force from the water. When the limiting diameter $D_{\max }$ of the neutrally suspended load is near the maximum diameter of the particles in viscous debris flow, this mixture flow acts like one-phase flow and can therefore be considered as a pseudo-one-phase flow. In that case, the grain-size distribution of viscous flow is no longer important in establishing the physical model. This study focuses on pseudo-one-phase flow and discusses the similarity laws for the confluence of debris flow and main river, neglecting the wide grain-size distribution.

A case study is carried out for the debris flow that occurred on 13 August 2010, in the Wenjia Gully. After satisfying the similarity scales, i.e., roughness scale, kinematic viscosity coefficient scale, and momentum ratio scale, the deposition terrain is simulated well in the model test. It is concluded that the torrential rain after the debris flow event complicated boundary conditions, the unsteady density of debris flow in nature and the correct value of the lost potential energy are the probable reasons for the deviations of the model test results from the prototype values.

Acknowledgements. The authors thank the support from the National Natural Science Foundation of China (Grant No. 50979064), open fund program of SKLH, Sichuan University, China (Grant No. 1312) and Key scientific research fund of Xihua University (Grant No. z1320404).

Edited by: P. Tarolli

Reviewed by: V. D'Agostino and two anonymous referees

\section{References}

Armanini, A.: Physical modeling of Debris-Flow, Proceedings of the International Symposium on Debris Flow and Flood Disaster, Emeishan, 1991.

Benda, L.: The influence of debris flows on channels and valley floors in the Oregon coast range, USA, Earth Surf. Proc. Land., 15, 457-466, 1990.

Benda, L. E., Andras, K., Miller, D., and Bigelow, P.: Confluence Effects in Rivers: Interactions of Basin Scale, Network Geometry, and Disturbance Regimes, Water Resour. Res., 40, W05402, doi:10.1029/2003WR002583, 2004.

Brufau, P., Garcia-Navarro, P., Ghilardi, P., Natale, L., and Savi, F.: 1D mathematical modelling of debris flow, J. Hydraul. Res., 38, 435-446, 2000.

Biron, P., Best, J. L., and Roy, A. G.: Effects of bed discordance on flow dynamics at open channel confluences, J. Hydraul. Eng., 122, 676-682, 1996.

Costa, J. E.: Physical geomorphology of debris flows, in: Developments and applications of geomorphology, edited by: Costa, J. E. and Fleisher, P., Springer-Verlag Berlin Heidelberg, Berlin, 268317, 1984.

Davies, T. R.: Dynamically similar small-scale debris flow models, International workshop on floods and inundations related to large earth movements, Proceedings of IAHR, A12.1-A12.11, 1993.

Fei, X. J. and Zhu, P. Y.: Viscosity of debris flow and its determination method, Journal of Railway Engineering, 9-16, 1986 (in Chinese).

Fuchs, S., Kaitna, R., Scheidl, C., and Hübl, J.: The application of the risk concept to debris flow hazards, Geomechanics and Tunnelling, 1, 120-129, 2008.

Hungr, O., Evans, S. G., Bovis, M. J., and Hutchinson, J. N.: A review of the classification of landslides of the flow type, Environ. Eng. Geosci., 7, 221-238, 2001.

Iverson, R. M.: Physics of debris flows, Rev. Geophys., 35, 245296, 1997.

Iverson, R. M. and Denlinger, R. P.: Flow of variably fluidized granular masses across three-dimensional terrain: 1. Coulomb mixture theory, J. Geophys. Res., 106, 537-552, 2001.

Johnson, P. C. and Jackson, R.: Frictional-collisional constitutive relations for granular materials with application to plane shearing, J. Fluid Mech., 167, 67-93, 1987. 
Lee, B.: The influence of debris flows on channels and valley floors in the Oregon Coast Range, USA, Earth Surf. Proc. Land., 15, 457-466, 1990.

Liu, C. Z.: Analysis on genetic model of Wenjiagou debris flow in Wenchuan earthquake area, Sichuan, Geol. Rev., 58, 709-716, 2012 (in Chinese).

Liu, X. L. and Lei, J. Z.: A method for assessing regional debris flow risk: an application in Zhaotong of Yunnan province (SW China), Geomorphology, 52, 181-191, 2003.

Miller, D. J. and Burnett, K. M.: A probabilistic model of debrisflow delivery to stream channels, demonstrated for the Coast Range of Oregon, USA, Geomorphology, 94, 184-205, 2008.

Ni, J. R. and Wang, G. Q.: Conceptual two phase flow model of debris flow: I. Theory, J. Geogr. Sci., 53, 66-76, 1998 (in Chinese).

Ni, J. R., Wang, G. Q., and Zhang, H. W.: The basic theory of solidliquid two phase flow and the new application, Science press, Beijing, China, 1991 (in Chinese).

Qian, N. and Wan, Z. H.: Research review of the exercise of hyperconcentrated flows, J. Hydraul. Eng., 5, 27-34, 1985 (in Chinese).

Ramamurthy, A., Carballada, L., and Tran, D.: Combining Open Channel Flow at Right Angled Junctions, J. Hydraul. Eng., 114, 1449-1460, 1988.

Rickenmann, D.: Empirical relationships for debris flows, Natural Hazards, 19, 47-77, 1999.

Rickenmann, D., Weber, D., and Stepanov, B.: Erosion by debris flows in field and laboratory experiments, in: Proceedings of the 3rd International Conference on Debris-flow Hazards Mitigation, 883-893, 2003.

Rickenmann, D., Laigle, D., McArdell, B. W., and Hübl, J.: Comparison of 2D debris-flow simulation models with field events, Comput. Geosci., 10, 241-264, 2006.

Schoklitsch, A.: Handbuch des wasserbaues, Springer-Verlag, New York, 1950.

Scott, K. M., Macías, J. L., Naranjo, J. A., Rodríguez, S., and MeGeehin, J. P.: Catastrophic Debris Flows Transformed from Landslides in Volcanic Terrains: Mobility, Hazard Assessment, and Mitigation Strategies, US Geological Survey Professional Paper 1630, 1-71, 2001.
Sha, Y. Q.: Introduction of debris flow kinetics, China Industry Press, Beijing, China, 1965 (in Chinese).

Sichuan Surveying and Design Institute of Water Resources: Survey report of " 8.13 " debris flow in Qingping country, Sichuan Province, 27-35, 2010 (in Chinese).

Takahashi, T.: Debris flows, Balkema, Rotterdam, 1991.

Vincenzo, D., Matteo, C., and Lorenzo, M.: Field and laboratory investigations of runout distances of debris flows in the Dolomites (Eastern Italian Alps), Geomorphology, 115, 294-304, 2010.

Wang, G. Q.: Kinematic theory and experimental research of solidliquid two phase flow and granular flow, $\mathrm{PhD}$ thesis, Tsinghua University, 1989 (in Chinese).

Wang, Y. Y.: Rheological characteristics of debris flow, J. Sediment Res., 2, 74-78, 1982 (in Chinese).

Wang, Z. Y., Cui, P., and Yu, B.: The mechanism of debris flow and drag reduction, Journal of Natural Disasters, 10, 37-43, 2001 (in Chinese).

Wu, X. P. and Huang, W. J.: The establishment of the roughness table in natural river channel and the discussion of the semiempirical formula, Hydrology, 2, 21-26, 1986 (in Chinese).

Whipple, K. X.: Open-Channel flow of Bingham fluids: Application in debris-flow research, J. Geol., 105, 243-262, 1997.

Xu, Q., Zhang, S., Li, W. L., and van Asch, Th. W. J.: The 13 August 2010 catastrophic debris flows after the 2008 Wenchuan earthquake, China, Nat. Hazards Earth Syst. Sci., 12, 201-216, doi:10.5194/nhess-12-201-2012, 2012.

Xu, Y. N., Liang, Z. Y., Su, X. B., and Wang, L.: Physical modeling of debris flow in the experimental flume, Journal of Natural Disasters, 9, 105-110, 2000 (in Chinese).

Yu, B., Ma, Y., and Wu, Y. F.: Investigation of severe debris flow hazards in Wenjia gully of Sichuan province after the Wenchuan earchquake, J. Eng. Geol., 18, 827-836, 2010 (in Chinese).

Zhang, H. W., Jiang, E. H., Zhao, X. J., and Zhang, Q.: Model similarity conditions of hyper-concentrated flood of the yellow river, Yellow River, 4, 1-3, 1995 (in Chinese).

Zhu, P. C.: Classification of muddy water sediment laden flow and debris flow, J. Sediment Res., 2, 80-86, 1995 (in Chinese). 